\title{
Synthesis and characterization of magnetic $(\mathrm{Cr} 0.5 \mathrm{Mn} 0.5)(2) \mathrm{GaC}$ thin films
}

\author{
Andrejs Petruhins, Arni Sigurdur Ingason, Jun Lu, Fridrik Magnus, Sveinn Olafsson and \\ Johanna Rosén
}

\section{Linköping University Post Print}

\section{Tweet}

N.B.: When citing this work, cite the original article.

The original publication is available at www.springerlink.com:

Andrejs Petruhins, Arni Sigurdur Ingason, Jun Lu, Fridrik Magnus, Sveinn Olafsson and Johanna Rosén, Synthesis and characterization of magnetic (Cr0.5Mn0.5)(2)GaC thin films, 2015, Journal of Materials Science, (50), 13, 4495-4502.

http://dx.doi.org/10.1007/s10853-015-8999-8

Copyright: Springer Verlag (Germany) http://www.springerlink.com/?MUD=MP

Postprint available at: Linköping University Electronic Press http://urn.kb.se/resolve?urn=urn:nbn:se:liu:diva-118837 


\title{
Synthesis and characterization of magnetic $\left(\mathrm{Cr}_{0.5} \mathrm{Mn}_{0.5}\right)_{2} \mathrm{GaC}$ thin films
}

\author{
Andrejs Petruhins*, a), Arni Sigurdur Ingasonª, Jun Luª, Fridrik Magnus ${ }^{\text {b), }}$ \\ Sveinn Olafsson ${ }^{\mathrm{c}}$, Johanna Rosen ${ }^{\text {a). }}$ \\ a) Thin Film Physics, Department of Physics, Chemistry and Biology (IFM), Linköping University, SE-581 83 \\ Linköping, Sweden \\ ${ }^{b)}$ Department of Physics and Astronomy, Uppsala University, Box 530, SE-751 21 Uppsala, Sweden \\ ${ }^{c}$ Science Institute, University of Iceland, Dunhaga 3, IS-107 Reykjavik, Iceland
}

\begin{abstract}
Growth of $\left(\mathrm{Cr}_{0.5} \mathrm{Mn}_{0.5}\right)_{2} \mathrm{GaC}$ thin films from $\mathrm{C}, \mathrm{Ga}$, and compound $\mathrm{Cr}_{0.5} \mathrm{Mn}_{0.5}$ targets is reported for depositions on $\mathrm{MgO}(111), 4 \mathrm{H}-\mathrm{SiC}(0001)$ and $\mathrm{Al}_{2} \mathrm{O}_{3}(0001)$ with and without a $\mathrm{NbN}(111)$ seed layer. Structural quality is found to be highly dependent on the choice of substrate with $\mathrm{MgO}(111)$ giving the best results as confirmed by X-ray diffraction and transmission electron microscopy. Phase pure, high crystal quality MAX phase thin films are realized, with a Cr:Mn ratio of 1:1. Vibrating sample magnetometry shows a ferromagnetic component from $30 \mathrm{~K}$ up to $300 \mathrm{~K}$, with a measured net magnetic moment of $0.67 \mu_{\mathrm{B}}$ per metal $(\mathrm{Cr}+\mathrm{Mn})$ atom at $30 \mathrm{~K}$ and $5 \mathrm{~T}$. The temperature dependence of the magnetic response suggests competing magnetic interactions with a resulting non-collinear magnetic ordering.
\end{abstract}

Keywords: magnetism, thin films, magnetron sputtering, MAX phase

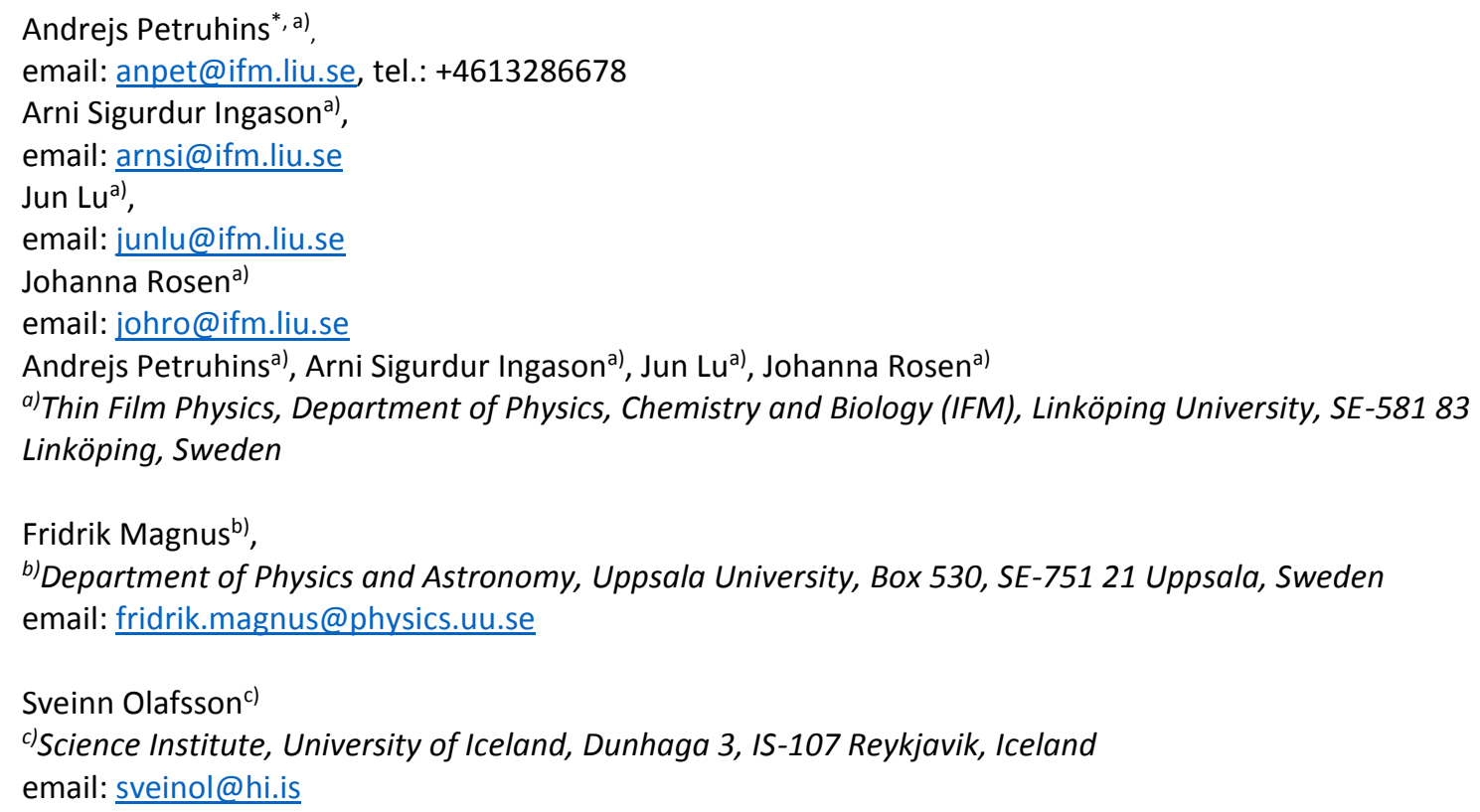




\section{Introduction}

MAX phases belong to a family of nanolaminated ternary compounds with the general composition $M_{n+1} A X_{n}(M-$ early transition metal, $A-\mathrm{A}$-group element, $X-\mathrm{C}$ or N, $n=1-3)$. Since their discovery in the 1960s[1], it took another 30 years before they attracted an increased attention due to their unique combination of metallic and ceramic properties. To date, more than 60 MAX phases have been synthesized and characterized[2].

If one of the elements in the MAX phase is partly substituted by another on either the $M, A$ or $X$ site, a solid solution can be formed. This is usually achieved by choosing substituting elements that have previously been used for MAX phase synthesis. Recently, in a quest for the first magnetic MAX phase, and fuelled by theoretical predictions[3], Mn was added as a new element to the MAX phase family. Initially, it was an alloying element in $\left(\mathrm{Cr}_{1-\mathrm{x}} \mathrm{Mn}_{\mathrm{x}}\right)_{2} \mathrm{AlC}$ [4-7] and $\left(\mathrm{Cr}_{1-\mathrm{x}} \mathrm{Mn}_{\mathrm{x}}\right)_{2} \mathrm{GeC}[8]$, providing the first magnetic MAX phases. Subsequent experimental studies on magnetic properties of MAX phases have not only been done on alloys containing $\mathrm{Mn}[9,10]$ but the topic has also been addressed for other MAX phases like, $\mathrm{Cr}_{2} \mathrm{AlC}[11]$, $\mathrm{Cr}_{2} \mathrm{GeC}[12]$ and $\mathrm{Cr}_{2} \mathrm{GaN}[13]$. Recently, a new MAX phase with Mn as the sole $M$ element, $\mathrm{Mn}_{2} \mathrm{GaC}$, was theoretically predicted[14] and experimentally confirmed[15], and it was also shown to have magnetic ordering.

Moreover, $\left(\mathrm{Cr}_{1-\mathrm{x}} \mathrm{Mn}_{\mathrm{x}}\right)_{2} \mathrm{GaC}$ solid solutions have been synthesized in bulk form, for $x=0.3$ showing magnetic transition temperatures at 38 and $153 \mathrm{~K}[5]$, and for nominally $x=0.5$ showing indications of ferrimagnetism[16]. However in the latter study, $x$ denoted the initial $\mathrm{Cr} / \mathrm{Mn}$ precursor ratio, and not a demonstrated Mn incorporation in the MAX phase structure. A more recent study has shown that precursor ratios cannot be unambiguously used to determine the composition of the final structure, and for both $\left(\mathrm{Cr}_{1-\mathrm{x}} \mathrm{Mn}_{\mathrm{x}}\right)_{2} \mathrm{AlC}$ and $\left(\mathrm{Cr}_{1-\mathrm{x}} \mathrm{Mn}_{\mathrm{x}}\right)_{2} \mathrm{GaC}$ the $\mathrm{Mn}$ solubility limit seems to be lower in bulk than in corresponding thin films[5].

No alloy thin films of $\left(\mathrm{Cr}_{1-\mathrm{x}} \mathrm{Mn}_{\mathrm{x}}\right)_{2} \mathrm{GaC}(0<x<1)$ have hitherto been reported. Such films, with high structural quality and a well-defined composition, could be used to investigate the effects of $\mathrm{Mn}$ alloying in the $\mathrm{Cr}_{2} \mathrm{GaC}$ phase, in line with previous work[8,4,7]. This is crucial to ensure that measured thin film properties are an effect of Mn alloying and do not originate from competing magnetic phases or compositional deviations from assumed alloy 
stoichiometry. The objective of this study is to investigate the effect of $\mathrm{Mn}$ alloying in $\mathrm{Cr}_{2} \mathrm{GaC}$ films, in particular their magnetic properties, as prior investigations on this material in bulk form indicate magnetic characteristics. We have therefore grown $\left(\mathrm{Cr}_{1-\mathrm{x}} \mathrm{Mn}_{\mathrm{x}}\right)_{2} \mathrm{GaC}(x=0.50)$ thin films of high purity and high structural quality, and investigated in detail their structure, composition, and magnetic properties.

\section{Experimental details}

Films were deposited by magnetron sputter epitaxy (MSE) using three elemental targets: Carbon (99.99\% purity), compound $\mathrm{Cr} / \mathrm{Mn}$ with 50:50 at. \% (99.95\% purity) and gallium (99.9999\% purity). The base pressure in the deposition chamber was below $5 \times 10^{-9}$ Torr, and the Ar pressure was 4.5 mTorr. For Mn and C, 3 inch targets were used, confocally placed at a $35^{\circ}$ angle with respect to the substrate normal at a distance of $180 \mathrm{~mm}$. For Ga, a 2 inch sputtering target was prepared according to details described elsewhere[17], and placed directly below the substrate (on axis) at a distance of $180 \mathrm{~mm}$.

Sputtering targets were operated in constant current mode and were set to calibrated room temperature fluxes corresponding to $2: 1: 1$ for $\mathrm{Cr} / \mathrm{Mn}, \mathrm{Ga}$ and $\mathrm{C}$ respectively. The applied current process setpoints were then fine-tuned to optimize the resulting film composition at the synthesis temperature.

To investigate growth on different substrates with various lattice mismatches with respect to the MAX phase, films were grown on $\mathrm{Al}_{2} \mathrm{O}_{3}(0001), \mathrm{MgO}(111), 4 \mathrm{H}-\mathrm{SiC}(0001)$ with $4^{\circ}$ off-cut towards the [11̄20] direction as well as $\mathrm{Al}_{2} \mathrm{O}_{3}(0001)$ with a deposited $\sim 15 \mathrm{~nm}$ thick $\mathrm{NbN}(111)$ seed layer, which prior to deposition were cleaned in ultrasonic baths of acetone, ethanol and isopropanol for $10 \mathrm{~min}$, and then were kept at the deposition temperature of $600{ }^{\circ} \mathrm{C}$ for 60 minutes prior to deposition to ensure uniform temperature distribution.

The structural properties of the films were investigated through $\mathrm{x}$-ray diffraction (XRD) and X-ray reflectivity (XRR), using standard $\theta-2 \theta$ geometry, and pole figure measurements in a Panalytical Empyrean MRD with $\mathrm{Cu} \mathrm{K} \alpha$ radiation $(\lambda=1.54 \AA)$. The scans were obtained with the tube in line focus using a $\mathrm{Ge}(220)$ hybrid monochromator on the incident side and a $0.27^{\circ}$ collimator on the diffracted side, with or without a collimator slit depending on the measurement. To evaluate sample quality, high resolution rocking curves were performed using a channel cut Ge (220) analyzer on the diffracted side. The reflectivity data was fitted using the Panalytical X'pert Reflectivity software. 
The sample was prepared for cross-sectional (scanning) transmission electron microscopy, (S)TEM by conventional mechanical polishing and Ar-ion milling methods. TEM was performed using a Tecnai G2 TF20 UT electron microscope, operated at $200 \mathrm{kV}$. Images were acquired in TEM mode using a CCD camera. Energy dispersive $\mathrm{X}$-ray spectroscopy (EDX) was performed in STEM mode. STEM imaging and EDX-mapping was performed on the doubly corrected Linköping $\operatorname{Titan}^{3}$ 60-300. The STEM images were recorded by the high-angle annular dark-field (HAADF) detector. The same electron probe was used for the STEM-EDX mapping, employing Super-X detectors.

The magnetic response of the sample was measured in a vibrating sample magnetometer (VSM) in the temperature range 30-300 K with the magnetic field applied parallel to the film plane. All temperature changes were done with no magnetic field applied. The sample was first cooled down to the lower temperature followed by magnetization measurement at different fields and afterwards heating up to next measurement temperature. The magnetic response of the $\mathrm{MgO}$ substrate was measured separately, as a function of temperature, and subtracted from the total substrate-film signal. It should be noted that measurements were performed also below $30 \mathrm{~K}$ but in this temperature range the non-linear $\mathrm{MgO}$ background could not be unambiguously separated from the signal originating from the MAX phase. Hence, the low temperature analysis is beyond the scope of the present work.

\section{Results and discussion}

\section{A. Structural characterization}

XRD analysis of a thin film grown on a $\mathrm{MgO}(111)$ substrate for 10 minutes is shown in figure 1. Apart from MgO 111 and 222 peaks, only basal plane MAX phase peaks can be seen, with no traces of other crystalline phases. The expected epitaxial relationship between film and substrate is $[11 \overline{2} 0]_{\mathrm{MAX}} \|[10 \overline{1}\rceil_{\mathrm{MgO}}$ in the film plane and $[0001]_{\mathrm{MAX}} \|[111]_{\mathrm{MgO}}$ out of the plane. The inset of figure 1 shows XRR data (dots) fitted with a single layer model (line), which gives a film thickness of $33.5 \pm 0.6 \mathrm{~nm}$. The estimated roughness and density of the film is $1.7 \pm 0.6$ $\mathrm{nm}$ and $6.4 \pm 0.4 \mathrm{~g} / \mathrm{cm}^{3}$, respectively. Measurements of the asymmetric (1013) and in-plane (112̄0) plane spacing gave the lattice parameter $\mathrm{a}=2.897 \pm 0.001 \AA$, whereas $\mathrm{c}=12.596 \pm 0.002 \AA$ was determined from (0006) plane spacing. These lattice parameters yield a unit cell volume of $91.55 \pm 0.08 \AA^{3}$. Comparing these values to pure $\mathrm{Cr}_{2} \mathrm{GaC}[17]$ ( $\mathrm{a}=2.90 \AA$ and $\mathrm{c}=12.62 \AA)$ and $\mathrm{Mn}_{2} \mathrm{GaC}[15](\mathrm{a}=2.90 \AA$ and $\mathrm{c}=12.57 \AA)$ for thin films on the same type of substrate and of similar thickness, the in-plane lattice parameter does not change significantly 
over the full range of $\mathrm{Cr} / \mathrm{Mn}$ ratios, while the c lattice parameter lies approximately in the middle between values of $\mathrm{Cr}_{2} \mathrm{GaC}$ and $\mathrm{Mn}_{2} \mathrm{GaC}$, consistent with what one might expect from Vegard's law[18] for a composition of $\left(\mathrm{Cr}_{0.5} \mathrm{Mn}_{0.5}\right)_{2} \mathrm{GaC}$.

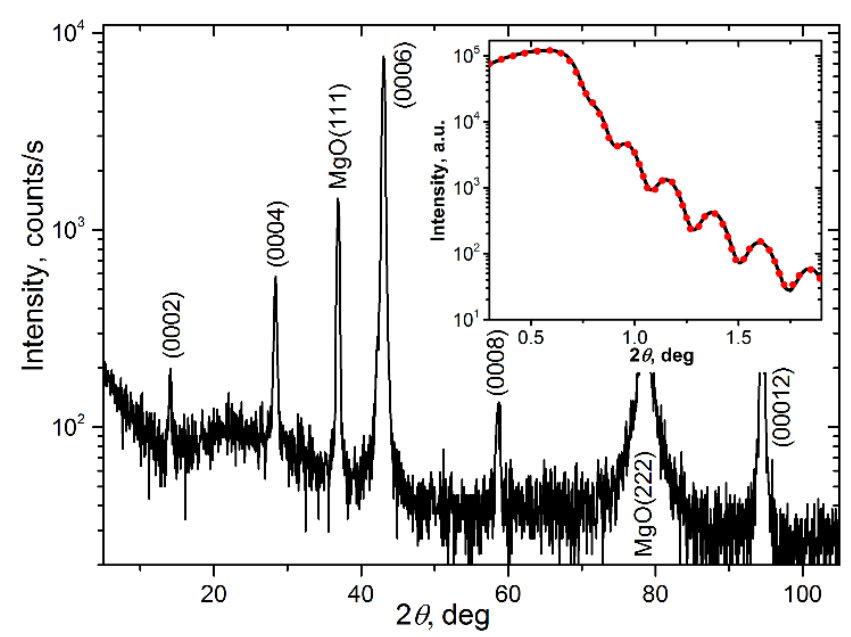

Figure 1. $\mathrm{XRD} \theta-2 \theta$ scan of a $\left(\mathrm{Cr}_{1-\mathrm{x}} \mathrm{Mn}_{\mathrm{x}}\right)_{2} \mathrm{GaC}$ thin film grown on $\mathrm{MgO}(111)$. The inset shows $\mathrm{XRR}$ measurement data (dots), along with a fitted curve (line).

A series of samples with different thickness were also grown on $\operatorname{MgO}(111)$ substrates. The thickness of a $34 \mathrm{~nm}$ and a $95 \mathrm{~nm}$ sample was determined from XRR, whereas samples of 190 and $\sim 570 \mathrm{~nm}$ were approximated from the calculated growth rate of the samples measured by XRR. Evolution of lattice parameters with a changed film thickness was evaluated by XRD, showing no change in the in-plane lattice parameter $a$. The $c$ lattice parameter, however, decreases slightly with increasing film thickness, from $12.596 \pm 0.002 \AA$ for the $34 \mathrm{~nm}$ film to $12.584 \pm 0.002 \AA$ for the $\sim 570 \mathrm{~nm}$ film, which could indicate film relaxation.

Figure 2(a). shows the low magnification TEM image of the film (middle) and substrate (bottom). The top layer is the glue remaining from the sample preparation process. The film consists of uniform high quality epitaxial MAX phase of $\sim 33 \mathrm{~nm}$ thickness, consistent with the XRR analysis. A grain size above at least $150 \mathrm{~nm}$ allows identification of uninterrupted MAX phase basal planes throughout the film section presented in (a). Figure 2(b) shows higher resolution epitaxial MAX phase throughout the whole film thickness. A HAADF image is shown in figure 2(c) and the same area is mapped with EDX. Elemental maps in figure 2(d), (e) and (f), show a uniform elemental distribution of the $\mathrm{Cr}, \mathrm{Mn}$ and Ga content in the MAX 
phase structure, also evident from the EDX spectrum in $(\mathrm{g})$, which yields an atomic ratio of approximately 35:34:31 for $\mathrm{Cr}, \mathrm{Mn}$ and $\mathrm{Ga}$ respectively. Apart from the aforementioned elements, $\mathrm{C}$ and $\mathrm{Ti}$ can also be seen, where $\mathrm{C}$ is a constituent of the MAX phase and $\mathrm{Ti}$ is residue from the sample preparation process (the sample is mounted in a Ti grid).

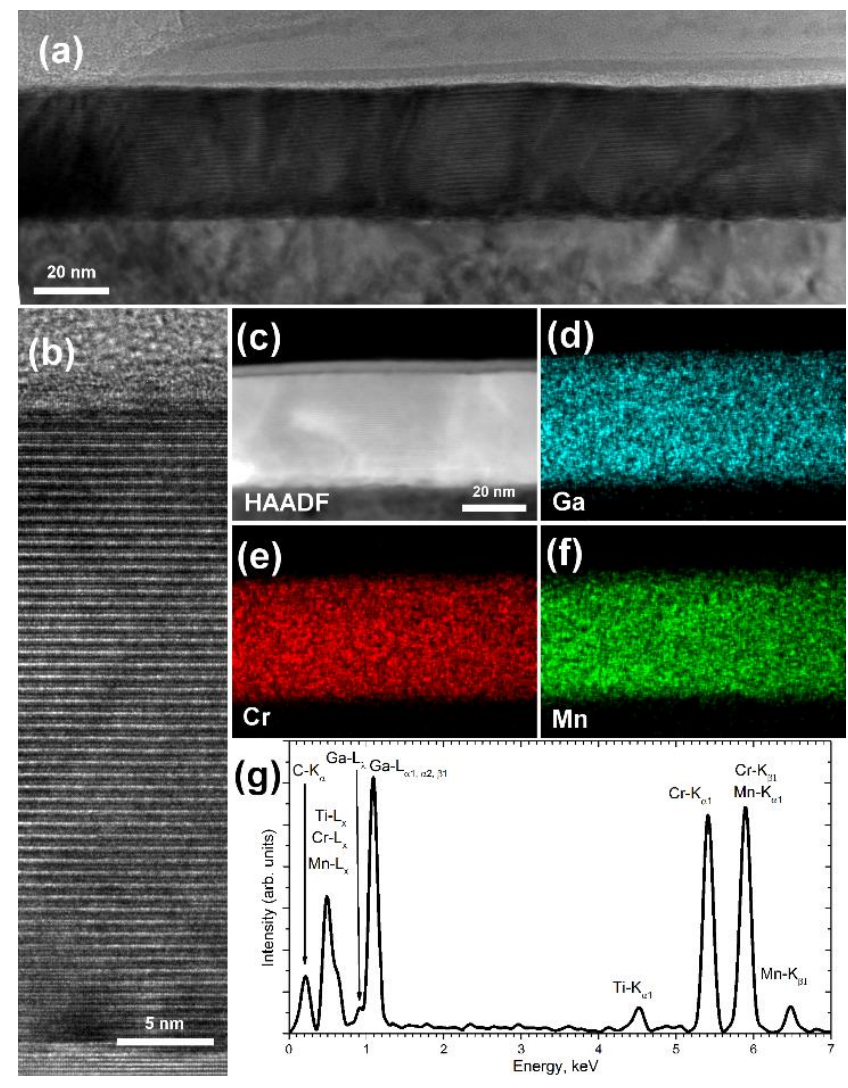

Figure 2. TEM analysis of a $\left(\mathrm{Cr}_{0.5} \mathrm{Mn}_{0.5}\right)_{2} \mathrm{GaC}$ thin film grown for 10 minutes. (a) Low magnification micrograph of the film (middle) and substrate (bottom) with remains of the glue from the sample preparation process (top). (b) High magnification micrograph revealing epitaxial MAX phase layers throughout the film thickness. (c) HAADF image of the region where EDX mapping was performed using Ga-L (d), Cr-K (e) and Mn-K (f) edges. (g) EDX spectrum obtained from the MAX phase region.

XRD analysis of a sample grown on $\mathrm{Al}_{2} \mathrm{O}_{3}(0001)$ substrate is shown in figure 3 . The basal plane MAX phase and $\mathrm{Al}_{2} \mathrm{O}_{3}(000 \ell)$ substrate peaks can be seen, as well as asymmetric (1013) and $(10 \overline{1} 0)$ peaks from the MAX phase, indicating growth of secondary oriented grains. Similar tilted grain growth on $\mathrm{Al}_{2} \mathrm{O}_{3}(0001)$ substrates has been previously observed for $\mathrm{Cr}_{2} \mathrm{GeC}$ thin films[19]. Tilting the sample to measure the asymmetric peak (1013), allows indirect determination of the lattice parameters to $\mathrm{a}=2.904 \pm 0.001 \AA$ and $\mathrm{c}=12.582 \pm 0.002 \AA$, resulting in a unit cell volume of $91.89 \pm 0.08 \AA^{3}$. 


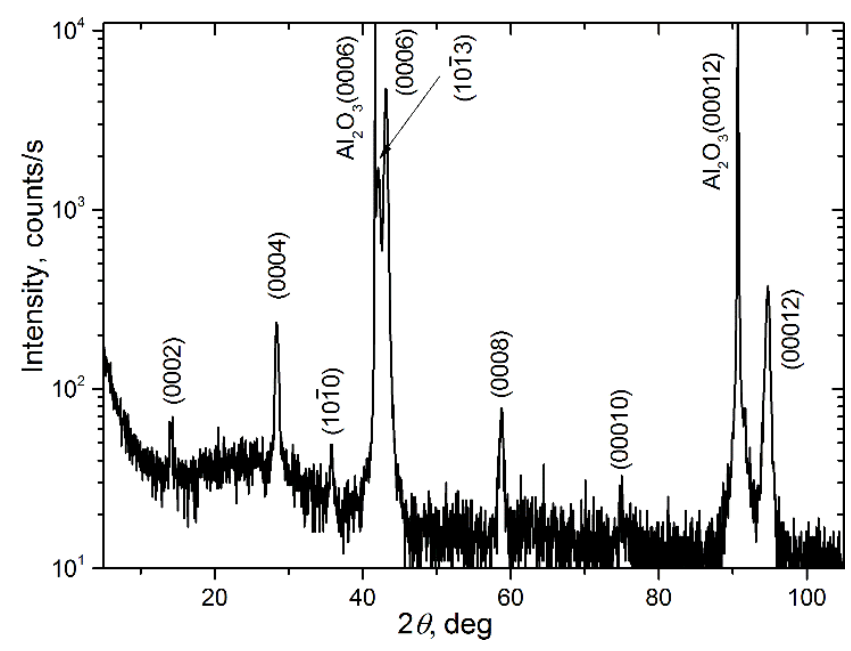

Figure 3. XRD $\theta-2 \theta$ scan of $\sim 34 \mathrm{~nm}$ thick $\left(\mathrm{Cr}_{1-\mathrm{x}} \mathrm{Mn}_{\mathrm{x}}\right)_{2} \mathrm{GaC}$ sample grown on $\mathrm{Al}_{2} \mathrm{O}_{3}(0001)$.

An XRD scan of a sample grown on $4^{\circ}$ off-cut $4 \mathrm{H}-\mathrm{SiC}(0001)$ for 30 minutes is shown in figure 4. MAX phase basal plane and substrate peaks, as well as peaks from tilted (1013) MAX phase grains are visible. The presence of (1013) grains is confirmed by doing off-axis XRD measurements (not shown) at $\chi=59.4^{\circ}$ (the angle between (0006) and (1013) planes), where the presence of (0006) spacing is evident. There are, however, minor peaks at $2 \theta \sim 31.9^{\circ}$ and $\sim 45.9^{\circ}$ originating most likely from the $\mathrm{Mn}_{3} \mathrm{GaC}$ inverse perovskite, marked as dots in figure 4 . These peaks are minute in comparison to MAX phase peaks, as the diffractogram shown in figure 4 is displayed in logarithmic scale on the intensity axis and these impurity phase peaks are almost 3 orders of magnitude lower in intensity than the most intense basal plane peak of the MAX phase. The $\theta$ offset was specified by the (0006) peak of the MAX phase, thus the peaks at $\sim 35.5^{\circ}$ and $\sim 75.5^{\circ}$ originate from the $4 \mathrm{H}-\mathrm{SiC}$ substrate, though of significantly reduced intensity. The expected epitaxial relationship between film and substrate is $[11 \overline{2} 0]_{\mathrm{MAX}}||[11 \overline{2} 0]_{4 \mathrm{H}-\mathrm{SiC}}$ in the film plane and $[0001]_{\mathrm{MAX}}||[0001]_{4 \mathrm{H}-\mathrm{SiC}}$ out of the plane. The lattice parameters determined from the XRD measurements give values of $\mathrm{a}=2.911 \pm 0.001 \AA$ and $\mathrm{c}=12.549 \pm 0.002 \AA$, and a unit cell volume of $92.09 \pm 0.08 \AA^{3}$. This is a slight increase in $a$ accompanied by a decrease in $c$, however, with an increase of the unit cell volume compared to corresponding films grown on both $\mathrm{MgO}(111)$ and $\mathrm{Al}_{2} \mathrm{O}_{3}(0001)$. 


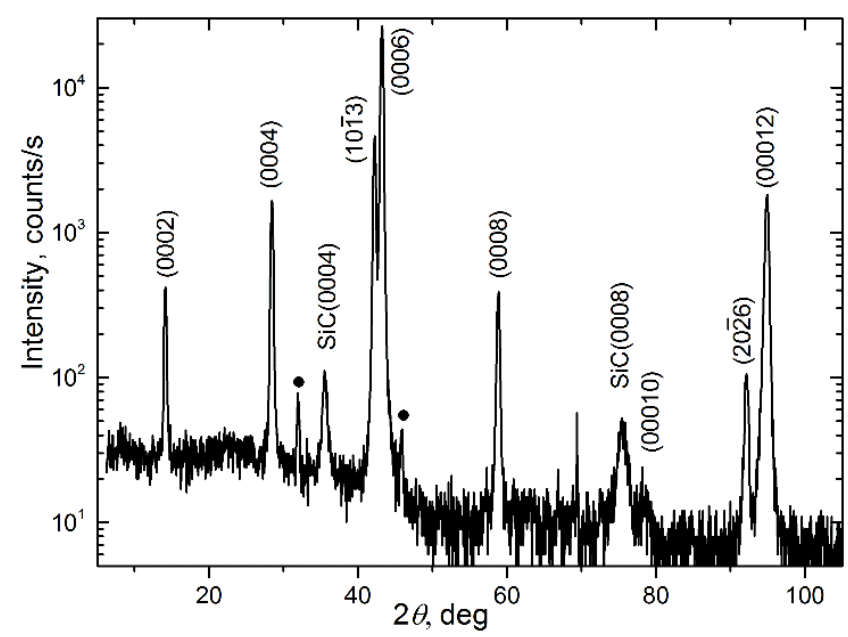

Figure 4. XRD $\theta-2 \theta$ scan of a $\sim 95 \mathrm{~nm}$ thick $\left(\mathrm{Cr}_{1-\mathrm{x}} \mathrm{Mn}_{\mathrm{x}}\right)_{2} \mathrm{GaC}$ sample grown on $4^{\circ}$ off-cut $4 \mathrm{H}-\mathrm{SiC}(0001)$. Black dots indicate the peaks corresponding to $\mathrm{Mn}_{3} \mathrm{GaC}$ inverse perovskite impurity phase.

A sample was grown for 3 hours on $\mathrm{Al}_{2} \mathrm{O}_{3}(0001)$ with a high quality $\sim 15 \mathrm{~nm}$ thick $\mathrm{NbN}(111)$ seed layer, to reduce the lattice mismatch and facilitate MAX phase growth. This resulted in a highly textured film, as confirmed by XRD analysis, see figure 5. Apart from very high intensity basal plane peaks, a relatively minor quantity of (1013) grains are present, as the $(10 \overline{1} 3)$ peak intensity is about 2 orders of magnitude lower than the intensity originating from (0006). Pole figure measurements show that apart from the major epitaxial orientation of the film, there are 4 other, minor, epitaxial directions for the MAX phase crystal (see figure 5 inset). These directions correspond to the MAX phase grains that are rotated $\pm 12^{\circ}$ and $\pm 24^{\circ}$ with respect to the majority of MAX phase grains. The intensity as measured by XRD of these grains is approximately 1 and 2 orders of magnitude lower for $\pm 12^{\circ}$ and $\pm 24^{\circ}$ rotated grains, as compared to the majority direction. Obtained lattice parameters for this film are $\mathrm{a}=2.908 \pm 0.001 \AA$ and $\mathrm{c}=12.552 \pm 0.002 \AA$, and resulting unit cell volume is $91.92 \pm 0.08 \AA^{3}$. 


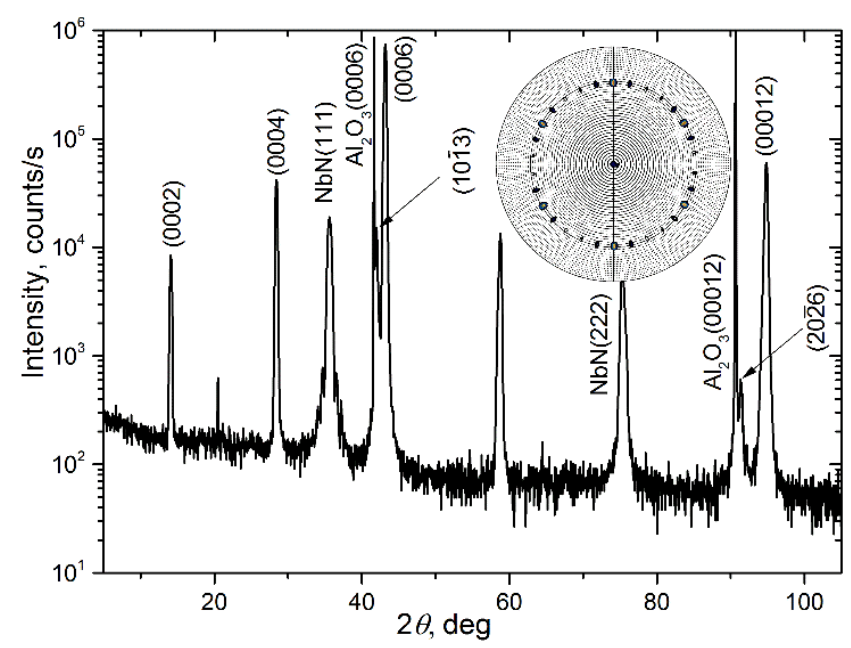

Figure 5. XRD $\theta-2 \theta$ scan of a $\sim 570 \mathrm{~nm}$ thick $\left(\mathrm{Cr}_{1-\mathrm{x}} \mathrm{Mn}_{\mathrm{x}}\right)_{2} \mathrm{GaC}$ sample grown on $\mathrm{Al}_{2} \mathrm{O}_{3}(0001)$ with $\mathrm{NbN}(111)$ seed layer. The inset shows a pole figure of the $(10 \overline{1} 3)$ MAX phase peak $\left(2 \theta=41.8^{\circ}\right)$.

Based on the analysis presented above of films deposited on different substrates, we can conclude that the $\mathrm{MgO}(111)$ substrate gives the best epitaxial films in terms of high structural quality with no indications of tilted grains. The $\mathrm{Al}_{2} \mathrm{O}_{3}(0001)$ substrate with or without $\mathrm{NbN}$ seed layer results in a high crystal quality film, as indicated by rocking curve measurements (full width at half maximum (FWHM) of the (0006) of the MAX phase of $0.011^{\circ}$ for the film grown on $\mathrm{Al}_{2} \mathrm{O}_{3}$ substrate without seed layer), however, an appreciable amount of secondary (1013) oriented MAX phase grains are present, indicating that even at optimal deposition conditions, the growth of only $(000 \ell)$ oriented MAX phase is most likely not possible. Growth of $\left(\mathrm{Cr}_{1-\mathrm{x}} \mathrm{Mn}_{\mathrm{x}}\right)_{2} \mathrm{GaC}$ on a $4^{\circ}$ off-cut $4 \mathrm{H}-\mathrm{SiC}$ substrate results in the presence of both secondary (1013) oriented MAX phase and other impurity phases, which indicates that this substrate requires different deposition conditions compared to those optimal for $\mathrm{MgO}(111)$. Rocking curve measurements performed on these samples showed that only films grown on $\mathrm{Al}_{2} \mathrm{O}_{3}$ substrate have a very narrow peaks, whereas films on other substrates showed much broader peaks with FWHM even up to of $2^{\circ}$ on $\mathrm{MgO}(111)$, which could indicate at some $\mathrm{MgO}$ substrates were of poor quality[20]. Pole measurements of all of the presented films were performed on the (1013) peak of the MAX phase. In pole figures (not shown) of all of the films, distinct peaks are seen at an angle of $\sim 59^{\circ}$, corresponding to the angle between $(000 \ell)$ and (10 $\overline{1} 3)$, indicating that the films are epitaxial.

The in-plane spacings of $\mathrm{Al}_{2} \mathrm{O}_{3}(0001), \mathrm{MgO}, 4 \mathrm{H}-\mathrm{SiC}$, and $\mathrm{NbN}$, to which the film is adjusting its lattice parameter, is $2.868 \AA, 2.981 \AA$, $3.084 \AA$, and $3.083 \AA$, respectively, see Table I. Comparing these values to the in-plane lattice parameter of the MAX phase (e.g. 
$2.897 \AA$ as grown on $\mathrm{MgO}(111)$ substrate), one would expect that $\mathrm{Al}_{2} \mathrm{O}_{3}(0001)$ is the only substrate for which the MAX phase thin films experience compressive stress, whereas the other substrates induce tensile stress. Comparing that to the actual MAX phase lattice parameter evolution on different substrates, we see that compared to films grown on $\mathrm{MgO}(111)$, MAX phase grown on $\mathrm{Al}_{2} \mathrm{O}_{3}(0001)$, $4 \mathrm{H}-\mathrm{SiC}(0001)$ and on a $\mathrm{NbN}$ seed layer on top of $\mathrm{Al}_{2} \mathrm{O}_{3}(0001)$ seem to have a slightly larger in-plane lattice parameter $a$, followed by a decrease in lattice parameter $c$, as expected. It is not, however, clear, why an expansion in-plane is present for films grown on $\mathrm{Al}_{2} \mathrm{O}_{3}(0001)$, as the adapting in-plane lattice spacing is smaller than that of $\mathrm{MgO}(111)$. This is possibly because on the surface of the $\mathrm{Al}_{2} \mathrm{O}_{3}(0001)$ crystal, there is more complex nucleation of the MAX phase, that may not be primarily governed by the hexagonal nucleation site with the spacing of $2.868 \AA$.

\begin{tabular}{|c|c|c|c|c|c|}
\hline \multicolumn{2}{|c|}{ Substrate } & $\mathrm{MgO}$ & $\mathrm{Al}_{2} \mathrm{O}_{3}$ & $\mathrm{NbN}$ & $4 \mathrm{H}-\mathrm{SiC}$ \\
\hline \multicolumn{2}{|c|}{$\begin{array}{l}\text { In-plane lattice } \\
\text { parameter, } \AA\end{array}$} & 2.981 & 2.868 & 3.083 & 3.084 \\
\hline \multirow[t]{2}{*}{ MAX } & $\mathrm{a}, \AA$ & 2.897 & 2.904 & 2.908 & 2.911 \\
\hline & c, $\AA$ & 12.595 & 12.581 & 12.552 & 12.552 \\
\hline \multicolumn{2}{|c|}{$\begin{array}{l}\text { Unit cell vol., } \\
\AA^{3}\end{array}$} & 91.55 & 91.89 & 91.92 & 92.09 \\
\hline
\end{tabular}

Table I. Summary of substrate in-plane lattice spacings matching MAX phase as well as lattice parameters and unit cell volumes of respective MAX phase grown on these substrates.

From all substrates used, only the $\mathrm{MgO}$ provides the possibility for growth of single phase, single orientation $\left(\mathrm{Cr}_{1-\mathrm{x}} \mathrm{Mn}_{\mathrm{x}}\right)_{2} \mathrm{GaC}$ thin films, as films grown on other substrates contained

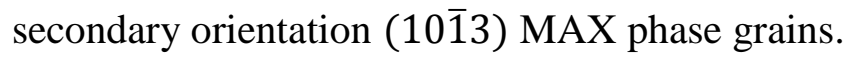

\section{B. Magnetic properties}

The in-plane magnetic response of the sample deposited on $\mathrm{MgO}$ was measured by VSM in the temperature range from 30 to $300 \mathrm{~K}$. Figure 6 shows the isothermal magnetization curves. The films show a ferromagnetic response with small hysteresis at low applied fields $(<0.2 \mathrm{~T})$, see inset. However, with increasing magnetic field the magnetization continues to rise and does not reach saturation even at $5 \mathrm{~T}$ for temperatures at and above $50 \mathrm{~K}$. The temperature 
dependence of the magnetization, expressed in net magnetic moment per $M$ atom $(\mathrm{Cr}+\mathrm{Mn})$ at 5 $\mathrm{T}, m_{5 \mathrm{~T}}$, and the remanent magnetization, expressed in net remanent moment per $M$ atom, are shown in figure 7 . Both decrease gradually with increasing temperature and no clear magnetic transition can be seen. The magnetic transition temperature is clearly above room temperature $(300 \mathrm{~K})$, for which $m_{5 \mathrm{~T}}$ is calculated to be $0.19 \mu_{\mathrm{B}}$ per $M$ atom, the remanent moment is 0.004 $\mu_{\mathrm{B}}$ per $M$ atom, and the coercive field $8 \mathrm{mT}$. The $m_{5 \mathrm{~T}}$ measured at $30 \mathrm{~K}$ is calculated to be 0.67 $\mu_{\mathrm{B}}$ per $M$ atom, and this value appears to be the saturation magnetization. At $30 \mathrm{~K}$, remanent moment is $0.036 \mu_{\mathrm{B}}$ and coercive field is $12 \mathrm{mT}$. It is worth pointing out that the saturation seems to be reached also at $50 \mathrm{~K}$ with similar $m_{5 \mathrm{~T}}$ value within the experimental error margins. This magnetic moment per $M$ atom is the largest reported among Mn containing MAX phase alloy systems to date[8,15,7].

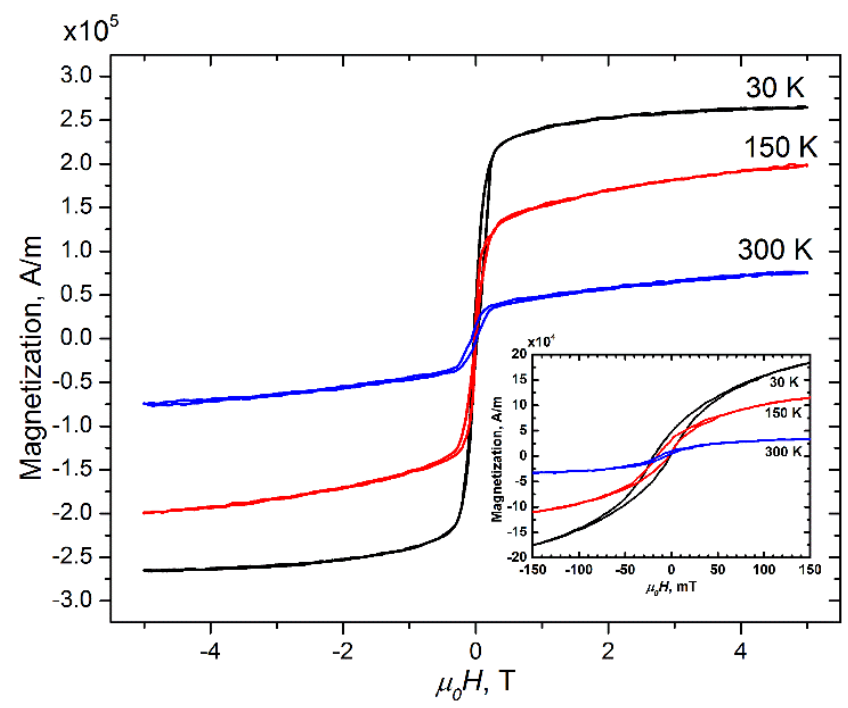

Figure 6. In-plane magnetization vs magnetic field measured at 30, 150 and $300 \mathrm{~K}$, showing an S-shape magnetic response at all temperatures. The inset expands the low-field region, showing a clear remanent magnetization.

The unconventional temperature dependence of the remanent and 5T magnetization, without a clear magnetic transition temperature, as well as the large saturation field, indicates that we do not have a simple collinear ferromagnetic ordering. A large saturation field alone could point towards a large magnetocrystalline anisotropy, but studies on a neighboring Mnbased magnetic MAX phase $\left(\mathrm{Cr}_{1-\mathrm{x}} \mathrm{Mn}_{\mathrm{x}}\right)_{2} \mathrm{GeC}$ have not shown the basal plane to have a magnetically hard axis[8]. Furthermore, the magnetization does not follow the $\left(T_{c}-T\right)^{\beta}$ temperature dependence characteristic of ferromagnets. Instead, the results suggest a noncollinear magnetic state with a small ferromagnetic component, which increases with decreasing temperature. Such an arrangement can be a result of competing magnetic interactions in the system, where ferromagnetic and anti-ferromagnetic states are nearly 
degenerate, as has been suggested for the neighboring $\left(\mathrm{Cr}_{1-\mathrm{x}} \mathrm{Mn}_{\mathrm{x}}\right)_{2} \mathrm{GeC}$ and closely related $\mathrm{Mn}_{2} \mathrm{GaC}[8,15]$. This delicate balance between different magnetic configurations leads to a complex temperature dependence, where the ferromagnetic state can be of lower energy at low temperatures.

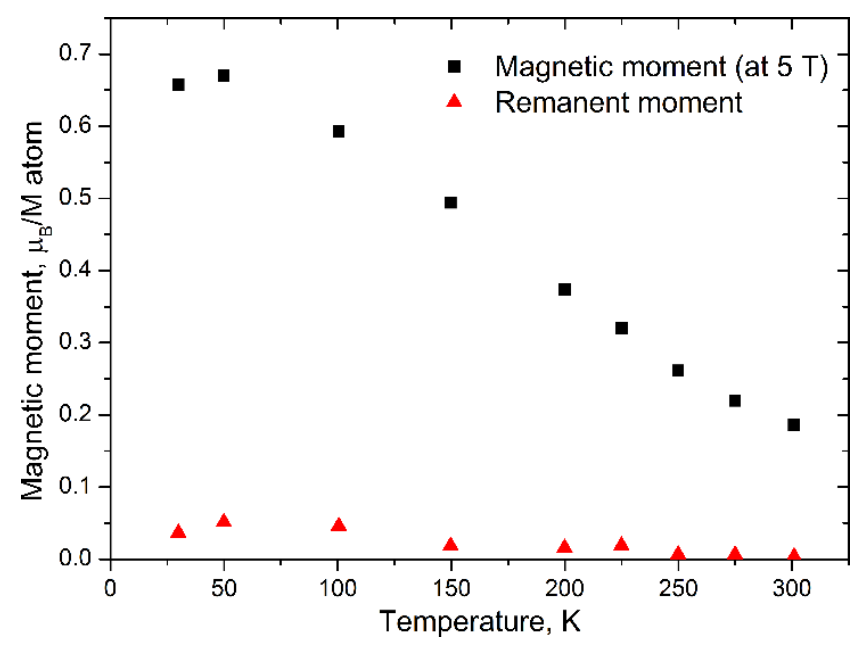

Figure 7. Average calculated net magnetic moment at $5 \mathrm{~T}$ and the average net remanent moment, expressed in $\mu_{B}$ per $M$ atom in the MAX phase, versus temperature.

The magnetic behavior presented here is different from what has been previously reported for bulk $\left(\mathrm{Cr}_{1-\mathrm{x}} \mathrm{Mn}_{\mathrm{x}}\right)_{2} \mathrm{GaC}$. In one study[16], for an assumed composition of $\mathrm{x}=0.5$, a paramagnetic behavior with weak ferrimagnetism was suggested as the ground state based on measurements at $5 \mathrm{~K}$. The reported temperature dependence of the magnetism, however, showed an approximately linear trend in the temperature range of $30-300 \mathrm{~K}$, and no remanence or coercivity was reported for any isothermal measurement. In another study on bulk MAX phase synthesis[5], it was shown that by using initial precursor molar ratios of 1:1 for Cr and $\mathrm{Mn}$, the final MAX phase composition included less $\mathrm{Mn}$, giving a nominal composition of $\left(\mathrm{Cr}_{0.7} \mathrm{Mn}_{0.3}\right)_{2} \mathrm{GaC}$. This material showed two magnetic transitions - at $38 \mathrm{~K}$ and at $153 \mathrm{~K}$, which did not correspond to any transition temperature of previously known magnetic phases in the $\mathrm{Cr}-\mathrm{Mn}-\mathrm{Ga}-\mathrm{C}$ system, or any of the observed impurity phases concluded from phase analysis. Hence, $\left(\mathrm{Cr}_{0.7} \mathrm{Mn}_{0.3}\right)_{2} \mathrm{GaC}$ was suggested to be magnetic. Comparing these results to those of the present paper, it is clear that the magnetic properties are strongly dependent on the Mn content.

\section{Conclusions}

We have demonstrated growth of epitaxial $\left(\mathrm{Cr}_{0.5} \mathrm{Mn}_{0.5}\right)_{2} \mathrm{GaC}$ thin films on $\mathrm{MgO}(111)$, $\mathrm{Al}_{2} \mathrm{O}_{3}(0001)$ and $4^{\circ}$ off-cut $4 \mathrm{H}-\mathrm{SiC}(0001)$ substrates. Deposited films are smooth and exhibit 
$\mathrm{X}$-ray reflectivity interference fringes for thicknesses of up to $\sim 100 \mathrm{~nm}$. TEM analysis confirms a high crystal quality and a local composition corresponding to $\left(\mathrm{Cr}_{0.5} \mathrm{Mn}_{0.5}\right)_{2} \mathrm{GaC}$. Films grown on $\mathrm{Al}_{2} \mathrm{O}_{3}(0001)$ are phase pure, however, tilted grain growth is evident, thus more optimal MAX phase growth is found on $\mathrm{MgO}(111)$ substrates.

Magnetic measurements on the film deposited on $\mathrm{MgO}$ reveal a ferromagnetic response from $30 \mathrm{~K}$ up to room temperature, with the net magnetization at $5 \mathrm{~T}$ decreasing gradually with increasing temperature. The magnetic moment measured at $5 \mathrm{~T}$ and $30 \mathrm{~K}$ is $0.67 \mu_{\mathrm{B}}$ per $M$ atom. The temperature dependence of the remanent and $5 \mathrm{~T}$ magnetization, as well as a large saturation field, suggest competing magnetic interactions in the system and non-collinear magnetic ordering.

\section{Acknowledgements}

The research was funded by the European Research Council under the European Community Seventh Framework Program (FP7/2007-2013)/ERC Grant agreement no [258509]. J. Lu acknowledges the KAW Foundation for the Ultra Electron Microscopy Laboratory in Linköping. J. Rosen acknowledges funding from the Swedish Research Council (VR) grant no. 642-2013-8020 and 621-2012-4425, from the KAW Fellowship program, and from the SSF synergy grant FUNCASE. S. Olafsson acknowledges funding from the Icelandic University Research fund.

\section{References}

1. Nowotny VH (1971) Strukturchemie einiger Verbindungen der Übergangsmetalle mit den elementen C, Si, Ge, Sn. Prog solid state chem 5 (0):27-70.

2. Barsoum MW (2013) MAX Phases: Properties of Machinable Ternary Carbides and Nitrides.

3. Dahlqvist M, Alling B, Abrikosov IA, Rosen J (2011) Magnetic nanoscale laminates with tunable exchange coupling from first principles. Phys Rev B 84 (22):220403.

4. Mockute A, Dahlqvist M, Emmerlich J, Hultman L, Schneider JM, Persson POÅ, Rosen J (2013) Synthesis and ab initio calculations of nanolaminated (Cr,Mn)_\{2\}AIC compounds. Phys Rev B 87 (9):094113.

5. Mockute A, Lu J, Moon EJ, Yan M, Anasori B, May SJ, Barsoum MW, Rosen J (2014) Solid Solubility and Magnetism upon Mn Incorporation in the Bulk Ternary Carbides Cr2AlC and Cr2GaC. Mater Res Lett 10.1080/21663831.2014.944676:1-7.

6. Mockute A, Persson POÅ, Lu J, Ingason AS, Magnus F, Olafsson S, Hultman L, Rosen J (2014) Structural and magnetic properties of $(\mathrm{Cr} 1-\mathrm{x} \mathrm{Mn} \times) 5 \mathrm{Al} 8$ solid solution and structural relation to hexagonal nanolaminates. J Mater Sci 49 (20):7099-7104.

7. Mockute A, Persson POÅ, Magnus F, Ingason AS, Olafsson S, Hultman L, Rosen J (2014) Synthesis and characterization of arc deposited magnetic $(\mathrm{Cr}, \mathrm{Mn}) 2 \mathrm{AIC}$ MAX phase films. Phys Status Solidi Rapid Res Lett 8 (5):420-423. 
8. Ingason AS, Mockute A, Dahlqvist M, Magnus F, Olafsson S, Arnalds UB, Alling B, Abrikosov IA, Hjörvarsson B, Persson POÅ, Rosen J (2013) Magnetic Self-Organized Atomic Laminate from First Principles and Thin Film Synthesis. Phys Rev Lett 110 (19):195502.

9. Tao QZ, Hu CF, Lin S, Zhang HB, Li FZ, Qu D, Wu ML, Sun YP, Sakka Y, Barsoum MW (2014) Coexistence of Ferromagnetic and a Re-entrant Cluster Glass State in the Layered Quaternary ( $\mathrm{Cr} 1-\mathrm{x}, \mathrm{Mnx}) 2 \mathrm{GeC}$. Mater Res Lett 2 (4):1-7.

10. Liu Z, Waki T, Tabata Y, Nakamura H (2014) Mn-doping-induced itinerant-electron ferromagnetism in $\$\{$ text $\{C r\}\}\{2\} \$ G e C$. Phys Rev B 89 (5):054435.

11. Jaouen M, Chartier P, Cabioc'h T, Mauchamp V, André G, Viret M (2013) Invar Like Behavior of the Cr2AIC MAX Phase at Low Temperature. J Am Ceram Soc 96 (12):3872-3876.

12. Jaouen $M$, Bugnet $M$, Jaouen $N$, Ohresser $P$, Mauchamp V, Cabioc'h T, Rogalev A (2014) Experimental evidence of $\mathrm{Cr}$ magnetic moments at low temperature in $\mathrm{Cr} 2 \mathrm{~A}(\mathrm{~A}=\mathrm{Al}, \mathrm{Ge}) \mathrm{C}$. J PhysCondens Mat 26 (17):176002.

13. Liu Z, Waki T, Tabata Y, Yuge K, Nakamura H, Watanabe I (2013) Magnetic ground state of the $\$\{M\}_{-}\{n+1\} A\{X\}_{-}\{n\} \$$-phase nitride $\operatorname{Cr} \$\{\}\{2\} \$ G a N$. Phys Rev B $88(13): 134401$.

14. Thore A, Dahlqvist M, Alling B, Rosén J (2014) First-principles calculations of the electronic, vibrational, and elastic properties of the magnetic laminate Mn2GaC. J Appl Phys 116 (10):-.

15. Ingason AS, Petruhins A, Dahlqvist M, Magnus F, Mockute A, Alling B, Hultman L, Abrikosov IA, Persson POÅ, Rosen J (2013) A Nanolaminated Magnetic Phase: Mn2GaC. Mater Res Lett 2 (2):89-93.

16. Lin S, Tong P, Wang BS, Huang YN, Lu WJ, Shao DF, Zhao BC, Song WH, Sun YP (2013) Magnetic and electrical/thermal transport properties of $\mathrm{Mn}$-doped $\mathrm{Mn}+1 \mathrm{AXn}$ phase compounds $\mathrm{Cr} 2-\mathrm{xMnxGaC}(0 \leq$ $x \leq 1$ ). J Appl Phys 113 (5):053502.

17. Petruhins A, Ingason AS, Dahlqvist M, Mockute A, Junaid M, Birch J, Lu J, Hultman L, Persson POÅ, Rosen J (2013) Phase stability of $\mathrm{Crn}+1 \mathrm{GaCn}$ MAX phases from first principles and $\mathrm{Cr} 2 \mathrm{GaC}$ thin-film synthesis using magnetron sputtering from elemental targets. Phys Status Solidi Rapid Res Lett 7 (11):971-974.

18. Vegard L (1921) Die Konstitution der Mischkristalle und die Raumfüllung der Atome. Z Physik 5 (1):17-26.

19. Eklund P, Bugnet $M$, Mauchamp V, Dubois S, Tromas C, Jensen J, Piraux L, Gence L, Jaouen M, Cabioc'h T (2011) Epitaxial growth and electrical transport properties of $\mathrm{Cr} 2 \mathrm{GeC}$ thin films. Phys Rev B 84 (7):075424.

20. Schroeder JL, Ingason AS, Rosén J, Birch J Beware of poor-quality MgO substrates: A study of MgO substrate quality and its effect on thin film quality. Journal of Crystal Growth http://dx.doi.org/10.1016/j.jcrysgro.2015.03.010. 